\title{
MEWUJUDKAN KOTA RESPONSIF MELALUI SMART CITY
}

\author{
Priskadini April Insani \\ Dosen Program Studi Administrasi Publik, FISIP - Universitas Merdeka Malang \\ email: priskadini@gmail.com
}

\begin{abstract}
Realizing Responsive City Through Smart City. Currently, the population growth is very fast, causing various problems especially in the city. The need for accessible, fast, appropriate and accurate information becomes the basic development of information technology in government. The creation of a smart city concept aims to give easiness for the community to overcome all the problems that occur.
\end{abstract}

Keywords: Smart City, Responsive, Information Technology

\section{PENDAHULUAN}

\section{Kesigapan Pemerintah Daerah Dalam Penerapan Smart City}

Dalam rangka penyelenggaraan pemerintahan daerah sesuai dengan amanat Undang-Undang Dasar Negara Republik Indonesia Tahun 1945, pemerintahan daerah, yang mengatur dan mengurus sendiri urusan pemerintahan menurut asas otonomi, diarahkan untuk mempercepat terwujudnya kesejahteraan masyarakat melalui peningkatan, pelayanan, pemberdayaan, dan peran serta masyarakat, serta peningkatan daya saing daerah dengan memperhatikan prinsip demokrasi, pemerataan, keadilan, keistimewaan dan kekhususan suatu daerah dalam sistem Negara Kesatuan Republik Indonesia.

Pelaksanaan otonomi daerah dan atau desentralisasi membawa sebuah tantangan bagi pemerintah daerah dalam memberikan layanan kepada masyarakat yang responsif. Hal ini mengacu bahwa desentralisasi adalah penyerahan wewenang pemerintahan oleh pemerintah pusat kepada daerah melalui kerangka sistem kenegaraaan dalam pengambilan keputusan. (Salam, 2007:86).
Sama halnya pengertian desentralisasi yang berdasarkan Undang-Undang No. 23 Tahun 2014 tentang Pemerintahan Daerah bahwa penyerahan wewenang pemerintahan oleh pemerintah kepada daerah otonom untuk mengatur dan mengurus urusan pemerintahan dalam sistem Negara Kesatuan Republik Indonesia.

Dethier (2000) argues that "the benign effects of decentralization hinge crucially on whether or not institutions are in place that mitigate the coordination and free-riding problems and the conflicts between different government entities that emerge due to decentralization. The difference seems to be due to the institutions governing the relationship between the central and subnational governments". Pemerintah daerah bertanggung jawab dalam pelaksanaan urusan wajib yang disebutkan dalam UndangUndang No. 23 Tahun 2014 tentang Pemerintahan Daerah pada Pasal 11 yaitu kewenangan daerah terdiri atas urusan pemerintahan wajib dan urusan pemerintahan pilihan.

Untuk urusan wajib, dalam hal ini lebih menekankan pada pelayanan publik. Sedangkan urusan pemerintahan kabupaten/ 
kota yang bersifat pilihan meliputi urusan pemerintahan yang secara nyata ada dan berpotensi untuk meningkatkan kesejahteraan masyarakat sesuai dengan kondisi, kekhasan, dan potensi unggulan daerah.

Kebanyakan dari masyarakat berpandangan bahwa kota lebih menarik daripada desa dan menjanjikan di masa depan. Dalam pengertian yang dimaksud dapat memperbaiki kualitas hidup dan kesejahteraannya.

\section{METODE PENELITIAN}

Metode penelitian yang digunakan ialah deskriptif dengan teknik pengumpulan data memanfaatkan data-data sekunder melalui kajian pustaka. Sedangkan analisis data menggunakan content analysis, yakni menelaah secara kritis terhadap data-data yang diperoleh dan menyimpulkan serta memberi rekomendasi atau saran-saran yang diperlukan.

\section{KAJIAN PUSTAKA}

Seiring dengan pertumbuhan penduduk yang relatif cepat menimbulkan berbagai permasalahan kota, seperti penurunan kualitas pelayanan publik, berkurangnya ketersediaan lahan pemukiman, kemacetan di jalan raya, kesulitan mendapatkan tempat parkir, membengkaknya tingkat konsumsi energi, penumpukan sampah, peningkatan angka kriminal, dan masalah-masalah sosial lainnya.

Saat ini, kebutuhan akan tersedianya informasi yang mudah di akses, cepat, tepat dan akurat menjadi salah satu dasar pengembangan pemanfaatan teknologi informasi di lingkungan pemerintahan.
Kebutuhan informasi ini sudah menjadi salah satu kebutuhan utama, karena pada umumnya pemerintah memiliki tugas dan tanggung jawab terhadap pelayanan masyarakat.

Salah satu kendala dalam pelayanan publik terutama di daerah, terkadang aparatur tingkat bawah atau biasa disebut street level bureaucracy cenderung kurang fleksibel, tidak responsif dan cenderung kaku terhadap aturan. Sehingga memicu terjadinya praktek KKN dalam penyelenggaraan pelayanan publik. Tidak adanya sistem intensif yang tepat, yang mampu mendorong para pejabat birokrasi untuk efisien, responsif, dan profesional juga menjadi salah satu faktor yang ikut membentuk kinerja birokrasi yang buruk (Dwiyanto, 2006).

Pelayanan publik yang diberikan oleh pemerintah begitu rendah. Adapun faktor yang menjadi penyebab antara lain:

a. Gaya manajemen yang terlalu berorientasi kepada tugas (task-oriented) menyebabkan aparatur kurang kreatif dalam peningkatan pelayanan publik (Kumorotomo, 2005).

b. Adanya budaya patron klien yang masih yang kaku sehingga hierarkis, tertutup, sentralistis, dan mempunyai nilai untuk menempatkan pimpinan sebagai pihak yang harus dihormati. Sehingga menganggap atasan sebagai segalanya menjadikan pelayanan menjadi tidak efisien.

c. Ketidakjelasan reward yang menyebabkan ketidakprofesionalan dalam pelayanan publik. Sehingga menyebabkan kinerja kurang maksimal. 
d. Rendahnya kualitas pendidikan baik formal maupun informal dari aparatur pemberi pelayanan (Dwiyanto, 2006).

SDGs dibangun secara partisipatif. PBB bekerja sama dengan beberapa lembaga mitranya telah menyelenggarakan survei warga, yang disebut sebagai Myworld Survey (http:// data.myworld2015.org/). Hasil survei hingga November tanggal 21 pukul 11.34 telah mengumpulkan sebanyak 8,5 juta lebih suara (persisnya 8.583.717 untuk semua negara). Untuk seluruh dunia, empat prioritas menjadi usulan yaitu pendidikan yang bermutu, kesehatan yang lebih baik, kesempatan kerja lebih baik, dan tata pemerintahan yang jujur dan tanggap. Untuk Indonesia, telah terkumpul 38 ribu suara (persisnya 38.422 suara), dengan prioritas yang sedikit berbeda dengan prioritas global yaitu; pendidikan yang bermutu, kesehatan yang baik, tata pemerintahan yang jujur dan tanggap, serta kesempatan kerja yang lebih baik. Baik agenda di dunia maupun di Indonesia berkeinginan agar tata pemerintahan baik.

Kunci sukses pemerintahan yang baik salah satunya berkaca pada pelayanan publik yang dianggap sudah tidak memadai lagi untuk mengatasi permasalahan. Oleh sebab itu dibutuhkan pendekatan yang terintegrasi untuk mengatasi segala permasalahan di kota, sehingga dilahirkanlah sebuah konsep Smart City.

Kota-kota yang disebut smart city adalah kota yang pada awalnya memiliki terobosan baru dalam penyelesaian masalah di kotanya dan sukses dalam meningkatkan performa kotanya. Salah satu dimensi terpenting dari smart city adalah memberikan pelayanan menggunakan teknologi terkini dan membangun infrastruktur yang pintar, sehingga dapat memberikan pelayanan yang efektif kepada seluruh masyarakat yang tinggal di kota (Sudaryono, 2014).

Konsep Smart city akan tercapai jika dapat dipahami dan didukung pada level tertinggi pemerintah kota dan mempunyai kontribusi terhadap kebutuhan masyarakat sehari-hari. Menurut Cohen, "Smart cities use information and communication technologies (ICT) to be more intelligent and efficient in the use of resources, resulting in cost and energy savings, improved service delivery and quality of life, and reduced environmental footprint-all supporting innovation and the low-carbon economy."

Nijkamp et al (2009) mendefinisikan kota cerdas sebagai kota yang mampu menggunakan sumber daya manusia (SDM), modal sosial, dan infrastruktur telekomunikasi modern untuk mewujudkan pertumbuhan ekonomi berkelanjutan dan kualitas kehidupan yang tinggi. Cohen (2010) menyebutkan bahwa kota cerdas diidentifikasikan pada 6 (enam) dimensi utama yaitu smart government (pemerintahan cerdas), smart economy (ekonomi cerdas), smart society (kehidupan sosial cerdas), smart mobility (mobilitas cerdas), smart environment (lingkungan cerdas), dan quality of live (hidup berkualitas). Dari enam (6) dimensi tersebut dalam penerapannya setiap kota dapat memfokuskan pada salah satu dimensi saja tergantung dari karakteristik kota dan urgensi permasalahan kotanya.

Smart city sudah dikenal baik di Indonesia maupun luar negeri. Berikut kotakota utama yang sudah 
mengimplementasikan konsep smart city misalnya Seoul, New York, Tokyo, Shanghai, Singapore, Amsterdam, London, Kairo, Dubai, Kochi dan Malaga.

Akan tetapi tidak mudah mewujudkan impian smart city tersebut, dibutuhkan pemikiran strategis dan kreatif. Strategis, mengandung pengertian dikerjakan secara terencana demi masa depan (futuristic), mulai dari identifikasi masalah, pengelompokan masalah, proses abstraksi, penentuan cara dan solusi masalah, serta perencanaan untuk implementasi (Nugraha, 2014). Kreatif, berarti kemampuan menghasilkan karya yang berguna dan baru, baik pada tataran individu maupun organisasi (Lazuardi, 2015).

Konsep smart city menurut Stepen Goldsmith (2014):

"a project to highlight local government efforts to use new technologies that connect breakthroughs in the use of big data analytics with community input to reshape the relationship between government and citizen".

Fenomena di negara maju, to improve government services and engagement with the public, the city has opened its data for use as raw material by developers outside government and policymakers inside city hall. To revolutionize its city planning process, it is using digital tools to plan the design of a new neighborhood to be built on the site of a long-abandoned steel plant. Then, too, Chicago is realizing the decadeold dream of the "smart city." Widespread sensors around the city will soon gather immense amounts of data that will be used to aid research. And the city government no longer simply offers some digital services. It now offers the tools citizens need to write their own apps.

Menurut Department for Business Innovation \& Skills (2013) ada lima aspek yang sangat penting untuk dapat dijadikan sebuah pendekatan dalam membangun kota impian masa depan, yakni:

a. a modern digital infrastructure, combined with a secure but open access approach to public reuseable data, which enables citizens to access the information they need, when they need it;

b. a recognition that service delivery is improved by being citizen centric:this involves placing the citizen's needs at the forefront, sharing management information to provide a coherent service, rather than operating in a multiplicity of service silos (for example, sharing changes of address more effectively), and offering internet service delivery where possible (at a fraction of the face to face cost);

c. an intelligent physical infrastructure ("smart" systems or the Internet of Things), to enable service providers to use the full range of data both to manage service delivery on a daily basis and to inform strategic investment in the city/community;

d. an openness to learn from others and experiment with new approaches and new business models;

e. transparency of outcomes/ performance, for example, city service dashboards to enable citizens to compare and challenge performance, establishment by establishment, and borough by borough. 


\section{PEMBAHASAN}

Kesimpulannya, smart city harus mampu membuat masyarakatnya aktif dalam beraktivitas, melakukannya dengan tenang, aman, nyaman, senang, dan bahagia tinggal didalamnya.

Konsep smart city di Singapura, being a smart city, smartly managed, is not only about information technology, or being in the vanguard of all types of applications of technology. being smart city-state is about a total operation as a world city with all economic and social dimensions consistent, integrated, and mutually supported. In the area of economic development, the untidy residual of anachronistic agricultural activity on the island was transformed form a rather primitive, traditionally operated, labour intensive, family based horticultural system into a modern, capital intensive agibusiness venture based on FDI, almost entirely on the grounds of economic rationality consistent with achievements in the leading sector of manufacturing and financial and bussiness services (Neville, 1992).

Indonesia sudah menerapkan smart city seperti Bogor, Jakarta, Bandung, Surabaya, dan Makassar. Seperti di Bogor membuat Bogor Green Room (BGR). Hal tersebut merupakan kolaborasi antara pemerintah Kota Bogor, ITB, dan Telkom Group ini akan digunakan sebagai pusat data dan informasi akurat sebagai bahan pengambilan keputusan dalam persoalan kependudukan, lingkungan, dan keseharian warga dibutuhkan strategi dengan menggunakan perangkat teknologi dalam rangka peningkatan pelayanan publik. Seperti memantau kondisi transportasi, kondisi darurat, dan peringatan terjadinya bencana.

Pelaksanaan smart city di Jakarta melalui Smart City Lounge. Konsep tersebut merupakan pusat kontrol untuk mengoprasikan smart city melalui TIK dan mampu menerima pengaduan masyarakat mengenai masalah sosial, macet, banjir, sampah, kriminalitas, pelayanan publik dan lain sebagainya.

Di Bandung terdapat Hay U untuk perizinan online, SIP untuk rapor Camat oleh warga, citizen complaint online, Silakip untuk memonitoring kerja Pemkot dan penggunaan Twitter sebagai media komunikasi warga.

Di Makasar telah mampu memantau kemacetan dan sistem pembayaran parkir online yang sudah on the track. Selain itu, Makasar juga sudah memiliki Makasar Smart Card yang bisa digunakan untuk kepentingan dalam urusan sistem pemerintahan dan pembayaran.

Kemudian di Surabaya adanya konsep traffic light yang diatur dengan Closed Circuit Televition (CCTV) dan Integrated Traffic System Management, di mana ketika antrean panjang di depan lampu lalu lintas, maka secara otomatis lampu berwarna merah akan berjalan lebih pendek.

SDG's (Sustainable Development Goals) dalam penerapan Smart City merupakan pembangunan berkelanjutan yang disepakati dunia dengan 17 program pembangunan berkelanjutan. 17 tujuan tersebut dapat dikelompokkan dalam empat pilar, yakni pembangunan manusia, pembangunan ekonomi, pembangunan lingkungan hidup, dan governance. Target ini berjalan selama 15 tahun yang dimulai pada tahun 2015-2030. SDG's sejalan dengan konsep smart city dalam 17 tujuan SDG's terdapat 2 tujuan yang merupakan program smart city, yaitu: Tujuan ke 11, make cities and 
human settlements (membuat kota dan pemukiman penduduk yang inklusif, aman, tangguh, dan berkelanjutan). Melalui strategi perwujudan sistem perkotaan nasional, pemenuhan standar perkotaan nasional, pembangunan kota hijau, pengembangan kota cerdas, peningkatan kapasitas tata kelola pembangunan perkotaan. Sedangkan tujuan ke 16, peaceful and inclusive societies (keadilan dan kedamaian). Melalui strategi mempromosikan proses pembangunan inklusif, menghormati hak-hak semua, melestarikan budaya, menghormati hak mereka untuk mewujudkan aspirasi pembangunan.

Sedangkan konsep smart city lebih luas dari digital city, karena smart city terdapat enam dimensi menurut Cohen yang dikutip dari fastcompany.com yaitu:

\section{a. Smart Government}

Smart government mengacu pada prinsip Good Governance. Kunci utama pemerintahan yang cerdas bertujuan untuk mengurangi kesenjangan di tingkat kota, kecamatan dan kelurahan adalah tidak hanya memeratakan pembangunan fisik di setiap daerah, tetapi juga peningkatan profesionalisme kinerja aparatur yang responsif terhadap kebutuhan masyarakat dengan didukung oleh kecanggihan teknologi.

b. Smart Economy

Seperti program pemberdayaan masyarakat melalui UMKM dan koperasi agar mendorong inovasi dan mengantisipasi persaingan usaha. Serta dapat menumbuhkembangkan rasa untuk berwirausaha. c. Smart People

Ditanamkannya nilai-nilai edukasi di dalam masyarakat dapat mendorong kehidupan sosial di perkotaan menjadi kondusif. Diantaranya elemen-elemen seperti kepercayaan, gotong royong, toleransi, penghargaan, saling memberi dan saling menerima serta kolaborasi sosial. Tata nilai ini perlu dipertahankan dalam kehidupan sosial masyarakat.

d. Smart mobility

Berkaitan dengan transportasi dan infrastruktur. Diharapkannya ada transportasi yang terpadu sehingga lebih efisien. Dengan ketersediaan sarana/ prasarana transportasi dan infrastruktur yang memadai, dapat meningkatkan pertumbuhan ekonomi dan kesejahteraan masyarakat. Pengelolaan infrastruktur kota yang dikembangkan di masa depan merupakan sebuah sistern pengelolaan terpadu dan diorientasikan untuk kepentingan publik.

\section{e. Smart Environment}

Dilihat dari segi penggunaan bangunan agar tidak berdampak pada kerusakan lingkungan serta cara mengelola sumber daya alamnya. Adanya kerusakan yang berdampak pada menurunnya mutu lingkungan pada dasarnya adalah akibat kelalaian atau kesengajaan yang dilakukan oleh masyarakat dan pemerintah.

f. Smart Living

Kualitas hidup masyarakat dapat dilihat dari segi kesehatan dan kemanan pada lingkungannya. 
Sehingga dapat mewujudkan lingkungan yang kondusif dan berkualitas bagi masyarakatnya.

\section{KESIMPULAN}

Berdasarkan hasil dari pembahasan yang telah dipaparkan, dapat ditarik kesimpulan bahwa sebuah konsep smart city ini bertujuan untuk memberikan kemudahan bagi masyarakat. Dalam hal ini memanfaatkan teknologi informasi yang digunakan secara maksimal secara tepat dan cepat.

\section{DAFTAR PUSTAKA}

Cohen, Daniel A. dan Paul Zarowin. 2010. Accrual-Based and Real Earnings Management Activities Around Seasoned Equity Offerings. Journal of Accounting \& Economics Vol. 50 No. 1: 2-19.

Department for Business, Innovation and Skills: Smart Cities. 2013. 1 Victoria Street London, Crown copyright.

Dethier, J.-J. Governance, decentralization and reform in China, India and Russia. (Ed.), Kluwer Academic Publishers, Boston, Dordrecht, London. 2000. viii +459 pp (403-404)

Dwiyanto, Agus. 2006. Reformasi Birokrasi Publik di Indonesia. Yogyakarta: Gadjah Mada University Press

Goldsmith, Stepen. 2014. The Responsive City: Engaging Communities Through DataSmart Governance. Ebook. Wiley.

Kumorotomo, Wahyudi. 2005. Akuntabilitas Birokrasi Publik, Sketa Pada Masa Transisi. Jogjakarta : Pustaka Pelajar

Lazuardi, Ahmad Lintang, 2015, Manajemen Strategis Inovasi dan Teknologi, terjemahan dari Strategic Management of Technological
Innovation, by Mellissa A. Schilling (2013), Yogyakarta, Penerbit Pustaka Pelajar.

Neville, W. 1992. Agribusiness in Singapore : a capital intensive service, Journal of Rural Studies, *(3), 241-55

Nijkamp. P (2008). "E pluribus unum". Research Memorandum, Faculty of Economics (Amsterdam: VU University Amsterdam).

Nugraha, M. Quadrat, 2014, Manajemen Strategis Pemerintahan, cetakan ketiga, Jakarta, Penerbit Universitas Terbuka

Salam, Setyawan Dharma., 2007. Manajemen Pemerintahan Indonesia, Jakarta: Djambatan

Sudaryono. 2014. Perilaku Konsumen Dalam Prespektif Pemasaran. Jakarta: Lentera Ilmu Cendekia.

\section{Sumber lain:}

http:// data.myworld2015.org/

https://www.fastcompany.com/3038818/the -smartest-cities-in-the-world-2015methodology 